Please do not remove this page

RMIT

UNIVERSITY

\title{
The entrepreneurial subjectivity of successful researchers
}

Sinclair, Jennifer; Cuthbert, Denise; Barnacle, Robyn

https://researchrepository.rmit.edu.au/esploro/outputs/9921860006101341/filesAndLinks?institution=61RMIT_INST\&index=null

Sinclair, J., Cuthbert, D., \& Barnacle, R. (2014). The entrepreneurial subjectivity of successful researchers. Higher Education Research and Development, 33(5), 1007-1019.

https://doi.org/10.1080/07294360.2014.890574

Document Version: Accepted Manuscript

Published Version: https://doi.org/10.1080/07294360.2014.890574

Repository homepage: https://researchrepository.rmit.edu.au

(c) 2014 HERDSA

Downloaded On 2023/04/26 20:41:04 +1000

Please do not remove this page 
Thank you for downloading this document from the RMIT Research Repository.

The RMIT Research Repository is an open access database showcasing the research outputs of RMIT University researchers.

RMIT Research Repository: http://researchbank.rmit.edu.au/

\section{Citation:}

Sinclair, J, Cuthbert, D and Barnacle, R 2014, 'The entrepreneurial subjectivity of successful researchers', Higher Education Research and Development, vol. 33, no. 5, pp. 1007-1019.

See this record in the RMIT Research Repository at:

https://researchbank.rmit.edu.au/view/rmit:24808

Version: Accepted Manuscript

Copyright Statement: (c) 2014 HERDSA

Link to Published Version:

http://dx.doi.org/10.1080/07294360.2014.890574 


\section{The entrepreneurial subjectivity of successful researchers}

Jennifer Sinclair, ${ }^{* 1}$ Denise Cuthbert* and Robyn Barnacle*

*School of Graduate Research, RMIT University, Melbourne, Australia

\section{Abstract}

This article begins the work of examining what kind of doctoral experiences positively influence researcher formation, and what other attributes may contribute to a successful research career. It reports preliminary findings from analysis of survey responses by a sample of successful mid-career researchers. The findings point to a positive doctoral experience and early establishment of research efficacy as important to researcher formation; and to successful researchers having a repertoire of 'soft skills', including a reflective capacity to recognise the importance of soft skills in their development and success. In addition, a key finding of this study is that successful researchers appear to have flexible, responsive and adaptive dispositions; what we call an 'entrepreneurial subjectivity.' We argue that an 'entrepreneurial subjectivity' is an important and underexamined characteristic that may be the making of, as well as what is required of, successful researchers.

Keywords: researcher formation; doctorate; productivity; success

Successful mid-career researchers are an ideal cohort to begin the work of identifying what in the doctoral experience contributes to the formation of a successful researcher and the qualities and attributes of successful researchers. To this end, we surveyed recipients of Australian 'Future Fellowships,' competitive four-year research grants awarded to those with between five and fifteen years postdoctoral experience. Future Fellowships are awarded by the Australian Research Council, the premier national research funding organisation.

The survey was designed to investigate how successful researchers are formed with a particular focus on the role and influence of the doctorate in this process. Preliminary findings from analysis of survey responses are outlined in this article. After introducing the study and outlining characteristics of the cohort, findings are discussed thematically concerning motivations for research, the doctoral experience, publication and preparation for

\footnotetext{
${ }^{1}$ Corresponding author. jennifer.sinclair@rmit.edu.au
} 
a research role, and to what factors participants in the survey attribute their research success.

The findings point overwhelmingly to a positive doctoral experience and early establishment of research efficacy as important to researcher formation; and to successful researchers having a repertoire of 'soft skills', including a reflective capacity to recognise the importance of soft skills to their success as researchers. In addition, a key finding of this study is that successful researchers appear to have flexible, responsive and adaptive dispositions; what we call 'an entrepreneurial subjectivity.' We argue that an 'entrepreneurial subjectivity' is an important and under examined characteristic that may be the making of, as well as what is required of, successful researchers.

\section{Background}

Two key issues concentrate the minds of many in the higher education sector: the doctoral experience, with a focus on timely completion as a measure of success; and researcher productivity subsequent to doctoral education. Both these areas have attracted considerable, but virtually separate, literatures. Our research begins to bridge this divide by seeking evidence from those most able to shed light on the potentially formative role of the doctorate in a productive research career, namely a cohort of people who have progressed through doctoral experiences to be deemed 'the best and the brightest mid-career researchers'(Australian Research Council, 2011).

The substantial literature devoted to identifying what factors contribute to research productivity is mostly quantitative (see, for example, Bentley, 2012; Hesli \& Mook Lee, 2011), as such it avoids or evades the question of the subjectivity of the productive researcher and neglects questions of identity formation in doctoral education (Green, 2005). Accordingly, this literature pays little detailed attention to the role of the doctorate in researcher formation and, in particular, the formation of productive researchers. This is the case despite the doctorate being widely recognised as training for a research role (Lee \& Boud, 2009). Where there is reference to the doctorate in productivity studies, it is generally restricted to aspects such as the location of the doctoral degree, time to completion and so on, or is structured as one of a number of 'dependent variables' - in some cases a very large number of dependent variables.

At the same time, the question of what constitutes doctoral 'success' warrants further attention. Arguably, how doctoral success is conceived varies according to the perspective of the multiple actors with investments in the PhD: the candidate, supervisors, the 
department, institution and, in Australia and other countries, the government that funds higher degrees by research. Timely and successful completion has typically been understood as the measure of doctoral 'success.' Perhaps this is a 'good enough' definition of success in view of historically and persistently high attrition rates amongst doctoral cohorts. Policy, funding and accountability regimes in Australia reward both the supervisor and the institution for doctoral completions. In Australia, a doctoral completion may also be counted as a research productivity output for supervisors for promotion and other purposes.

Handbooks on 'successful' supervision typically cover topics such as data collection, designing a research project, the literature review, thesis writing and so on (see, for example, Delamont, Atkinson \& Parry, 2007). The focus of such handbooks is biased towards the role of the supervisor in supporting thesis production and pays limited attention to how supervisors can assist candidates in the process of becoming a researcher. Moreover, although publishing during doctoral candidature is increasingly expected and receiving more attention (Aitchison, Kamler \& Lee 2010; Cuthbert and Spark, 2008; Raddon, 2011), publishing productivity is not yet deemed an explicit measure of doctoral success, nor is subsequent productivity of candidates widely deemed a measure of the quality of doctoral programs, although some studies have begun to use publication productivity as an indicator of the value of doctoral programs as an alternative to other ranking criteria (see, for example, Roy, Roberts and Stewart, 2006). Thus, there is a conceptual and practical disjunction between what is required for doctoral completion and subsequent researcher productivity. As a consequence, the influence and role of the doctorate in forming researchers who go on to successful research careers remains under-examined.

\section{About the research}

In 2008, the Australian Research Council awarded the first of five rounds of Future Fellowships to 'promote research in areas of critical national importance' by giving outstanding researchers incentives to conduct their research in Australia. The aim of the Future Fellowship Scheme is to attract and retain 'the best and brightest mid-career researchers' (Australian Research Council, 2011). Over a five-year period (2009-2013), 1000 Future Fellowships are to be awarded to outstanding mid-career researchers.

Our key research questions are: what role, if any, does the doctoral experience play in encouraging and enabling $\mathrm{PhD}$ graduates to become active academic researchers; and, correspondingly, what are the dispositions and motivations of productive researchers?

\section{Method}


As a first step in a larger project, we designed a survey aimed at examining researcher formation with a focus on the doctoral experience. Along with demographic questions, we asked: what had influenced respondents to undertake doctoral study; the nature of their doctoral experience, including writing and publication experiences; the supervisory relationship and research culture; motivations for undertaking research, and; to what factors they attribute their success as researchers.

By February 2012, when the survey was conducted, 600 awards had been made across three cohorts of Future Fellows awarded in 2009, 2010 and 2011 for funding commencing the following year. Our sample comprises 233 survey respondents from Future Fellows drawn from the first three cohorts.

The contact details of Future Fellows were obtained by accessing publicly available information from the Australian Research Council. Due to changes in institutional affiliation, some possible resignations from Fellowships, and contact information being unavailable, the pool of potential respondents was reduced from 600 to 544 . Thus our sample of 233 responses represents a return rate of around $42 \%$ to the survey. The survey instrument combined short answer, multiple choice and open-ended questions. Where respondents were asked to indicate the saliency of a particular item on a three point scale (i.e. 'to some extent'; 'to a great extent' or 'not at all'), numbers of those indicating 'to some extent' and 'to a great extent' are combined, except where otherwise noted.

\section{About the sample}

In terms of age, $42 \%$ of our Future Fellows are under 40 years of age while $48 \%$ are aged between 41 and 50 . This profile reflects the intention of the scheme to identify and support younger, mid-career academics. Most finished their PhDs when they were under 30 and 36\% completed their doctorates since 2001.

Reflecting Australian government research priorities since the 1990s, most of the sample are drawn from the natural and physical sciences: 178 or (76\%) of the sample work in the natural, biological or physical sciences, while 53 (22\%) work in the social sciences and humanities. The fields most represented include biological sciences ( $20 \%$ of science fields), physical sciences (16\%) and medical sciences (14\%). Just over a third of the sample received their PhDs from four Australian research intensive universities (11\% Australian National University; 9\% University of Queensland; 8\% University of Sydney; and 7\% University of Melbourne). A further third of the cohort (77 or 33\%) graduated from nonAustralian universities. 
In terms of gender, 147 (63\%) of the sample are men, while $86(37 \%)$ are women. Women are slightly over-represented in our sample relative to the population of Future Fellows, given that in each of the three years of the scheme roughly $70 \%$ of the awards went to men and $30 \%$ to women.

\section{Motivations for undertaking doctoral research and a continuing research career}

In seeking to understand how and when successful researchers are formed, we asked our cohort when they first became aware of research as an attractive career option. We were particularly interested in the extent to which their doctoral experience generated or cultivated desires to become researchers. We found that $68 \%$ were aware of research as an attractive career option before commencement of doctoral studies. Of these, a majority became aware of research as a career option during undergraduate study (34\%) or Honours (21\%). Only $19 \%$ of respondents became aware of a research career as an option during doctoral candidature. Interestingly, $12 \%$ of our respondents were aware of research as an attractive career option during high school or even earlier, with some expressing a desire to become a researcher since early childhood. Only a very small number of respondents (5) indicated they became aware of research as a career option after their doctoral candidature, during a post-doctoral appointment. It is also worth noting that some respondents, although not many (5), overtly rejected the proposition that research is an attractive career option, despite their own research success.

The relatively high percentages of those aware of a research career before commencing doctoral study, suggests that many in this cohort may have been predisposed or 'primed' to frame their doctoral experience as preparation for a research career, either independently of or in conjunction with supervisors and institutional framing of the role of the doctorate.

In our study we were also interested in investigating the factors informing decisions to undertake a doctorate and the relative saliency of each. We reasoned that understanding what influenced subsequently successful researchers to undertake doctoral study in the first place could provide clues as to how and why it is they go on to become successful researchers. To investigate, we asked respondents to rate on a three-point scale ('to some extent', 'to a great extent' or 'not at all') the influence of the following factors on their decision to undertake doctoral study: interest in a particular topic; general curiosity; honours experience; being awarded a scholarship; desire to attain a further qualification; other research experience; encouragement from an academic; and, contact with researchers in the school or any other influential factor. 
We found that the two highest scoring factors that influenced respondents 'to some' or 'a great extent' were 'interest in a particular topic' (94\%) and 'general curiosity' (86\%). These factors have been noted elsewhere as key motivations of doctoral candidates (Vitae, 2012; Walker, Golde, Jones, Conklin Bueschel \& Hutchings, 2008). This was followed by a desire to gain a further qualification (80\%). The fourth ranking factor in terms of saliency of influence is 'encouragement from an academic' (79\%). Reading between the lines it is possible to speculate that intrinsic interest in a topic, general intellectual curiosity and desire to gain a qualification are personal or internal drivers influencing a decision to undertake doctoral research but these personal interests and motivations are often coupled with encouragement from an academic. Such encouragement may function as external validation of aptitude and ability and desire to pursue this path.

As we are interested in the question of researcher formation we also asked respondents to comment on their motivations for doing research and publishing their findings. A majority of respondents (53\%) indicate they are motivated by curiosity, passion, or an intrinsic interest in the work itself. Examples of this type of motivation are as follows:

I am absolutely in love with my chosen field of research. It is all I have ever wanted to do and if I won the lottery tomorrow, I would still do it.

I gain personal satisfaction through pursuing intellectually stimulating questions, and by making a contribution to the broader field of scholarship that I am involved in, both through publishing research, and interacting with other researchers.

Discovery, discovery, discovery! Being the first to see or describe or understand something has always motivated my research. Publication is the fruit of this, though I try (hard though) to not make it the goal.

An additional $31 \%$ indicate they are motivated by altruistic reasons to conduct research, or by a combination of altruism and passion for research. For example:

I feel I can make a difference in people's health and ultimately their lives.

I fear that civilisation will collapse within my lifetime. Working to reduce that risk is very motivating.

My main motivation for conducting research and disseminating my findings is the hope that one day I can make a significant contribution to society and improve people's quality of life.

I love learning and answering new questions. This drives much of my passion for science and my drive to do more. It is my personal philosophy that science in a vacuum is of no use. The data we collect must be distributed to the scientific community so we can all learn, grow, advance science and challenge one another. 
Collected data stored in a file cabinet doesn't help science or the community advance.

These responses indicate that for a majority of those in our cohort (84\%) the intellectual curiosity and interest that influenced a decision to undertake doctoral study remain constant and that they remain engaged with and enthused by their research work through to midcareer.

A minority indicate they are motivated by what might be termed instrumental reasons for doing research. An example of this comparatively uncommon type of response is:

To achieve success in an academic career: job security, good lifestyle, job satisfaction.

\section{The doctoral experience}

Respondents were asked to indicate the level of enjoyment they experienced in relation to different aspects of doctoral research: the intellectual challenge; the process of research itself; the personal challenge; being part of a research community; the supervisory relationship, and; writing the thesis or exegesis. Again, respondents were asked to rate the relative degree of enjoyment on a three point scale: to 'a great extent', to 'some extent' and 'not at all.' The top two aspects of doctoral research that respondents indicate they enjoyed 'to some' or 'to a great extent' were the intellectual challenge (97\%) and the process of research itself (97\%), followed by 'the personal challenge' (92\%) and 'being part of a research community' (87\%). Overall, there are consistently high levels of enjoyment of all nominated aspects of doctoral candidature, with 'writing the thesis or exegesis' ranking as the least enjoyable aspect of doctoral study. Even as the least enjoyable aspect of doctoral study among this cohort, however, the percentage of those who enjoyed writing the thesis or exegesis 'to some' or 'to a great extent' is still a high $82 \%$.

Research participants appear to have enjoyed their doctoral experiences - the process of research itself as well as the intellectual challenge of research work. In light of responses to the question of key influences in making a decision to undertake the doctorate, it appears this cohort's doctoral experiences confirm their decision and that the key drivers of interest in their topic, curiosity, and a desire to gain a qualification, did not wane during the course of their degree. This contrasts with a recent international survey of graduate students in the US and Europe that found declining levels of interest in their work and declining levels of satisfaction with the graduate experience as they progressed through their study (Russo, 2011). By the final year of postgraduate study more than $50 \%$ were 'somewhat' or 'far less 
likely' to commence a research career since commencing their PhD. Notably, the main reason given for declining interest in pursuing a research career by a significant margin was that 'traditional research careers are too competitive', followed by becoming 'less interested in the type of work involved in a research career' $(2011,534)$.

We also asked respondents how well their doctorate prepared them for a research career. A majority, 72\%, agreed their doctoral experience prepared them for a research career 'to a great extent' and $26 \%$ responded it prepared them 'to some extent'. Some of the 130 respondents who elected to add a comment to this question made some qualifications about their doctoral experience as not covering all aspects of the researcher role, and some noted their development continued or began subsequent to doctoral candidature. The majority of these comments, however, were very positive, with only four notable exceptions. Examples of the kinds of positive comments are as follows:

[My PhD] gave me a great knowledge base of my field, set up collaborations, taught me how to write grants, papers etc., communicate with the public, patient groups and the media, lecture students, supervise research students etc.

My research was not just focused on analysing data and writing papers, but also involved all the logistical aspects like running studies, ethics, grant writing, etc.

One could say the PhD really was the beginning of the career, rather than a preparation.

Many of the skills I learnt during my PhD I still use today.

The supervisory experience can be extremely variable so we asked respondents to indicate the supportiveness of their supervisors in relation to eight dimensions: developing relevant skills and knowledge; mentoring in the practice of academic writing; presenting at conferences; publishing; developing relationships with others; gaining employment; developing confidence as a researcher; and, preparing proposals for research funding. 'Developing relevant skills and knowledge' is the dimension that most respondents indicate their supervisor offered either 'some' or 'a great deal of support' for, at $91 \%$. This was closely followed by the dimensions of 'developing your confidence as a researcher', 89\%, 'mentoring you in the practice of writing', 88\%, and 'publishing your work', $84 \%$.

The combined numbers of responses indicating supervisors offered 'some' or 'a great deal' of support are high across all dimensions, with the notable exception of 'preparing proposals for research funding'. Only 53\% indicate they had been offered support in this area. 
Brew, Boud and Namgung (2011) asked a large academic cohort a similar question about the extent to which the doctorate prepared them for independent research and teaching. Their findings contrast markedly with ours in that, although they note a positive relationship between doctoral study and independent research and teaching, their research: "did not indicate that doctoral studies had a strong influence on preparation for independent research practice" (2011: 56). By contrast, our cohort clearly indicates a strong sense of the doctoral experience as preparation for a research career. This suggests, unsurprisingly and perhaps also appropriately, that our cohort is not representative of the average Australian doctoral graduate or academic.

\section{Publication during the PhD and preparation for a research career}

As noted earlier, publication of research articles during the $\mathrm{PhD}$, while not yet a requirement of the $\mathrm{PhD}$, is becoming more integral to the core business of doctoral study. We asked our cohort questions about publication productivity and publication experiences as we speculated that efficacy and experience in this area may be crucial to a later research career.

A total of $92 \%$ of those who responded reported having published one or more articles in a refereed journal during doctoral candidature; and $50 \%$ of those reported publishing four or more articles in refereed journals during candidature. Only $7 \%$ did not publish refereed articles during doctoral candidature. We also asked participants to report other forms of publication during candidature including books, book chapters, and refereed and non-refereed conference papers. The number of respondents who reported none of these kinds of outputs was substantially higher than the category who reported that they published no refereed journal articles during doctoral candidature. These findings suggest our cohort may strategically target their writing efforts during candidature toward refereed journal articles. Such findings also appear to confirm work by Williamson and Cable (2003) that posits a link between productivity during doctoral candidature and early career productivity. Taken together the findings suggest that those who go on to successful research careers acquire publication experience and efficacy during doctoral candidature. This may represent a considerable advantage.

Respondents were also asked about the kind of publishing and writing they undertook, and specifically, whether they had co-authored papers with their supervisors 
during candidature. Eighty seven per cent reported they had co-published articles with their supervisors with many commenting positively on the value of this experience. In a study of the productivity of doctoral candidates, Chung and Petrick (2011) found that candidates who co-publish with supervisors are more productive during candidature than those who do not (Chung \& Petrick, 2011). This points to the potentially important role of the supervisor in establishing and encouraging writing and publication confidence and skills.

The central pedagogical role of the supervisor in encouraging publication is reinforced by responses to the question of whether the cohort attended professional development workshops on writing for publication during their candidature. Eighty three per cent reported they did not attend writing workshops or any other kind of writing development activity. Of the $34 \%$ who reported attending a writing workshop only $5 \%$ said that the workshops or activities were useful.

\section{Attributing success}

Given that this is a sample of high achievers, their views about what has led them to become successful researchers is of interest. Using an open-ended question to elicit reflection, we asked Future Fellows to comment on to what they attribute their success as a mid-career researcher. Our findings complement existing work on researchers' conceptions of higher research performance such as Bazeley's study (2010) which sought to build a conceptual model of research performance based on academics' perceptions of these dimensions. In the preliminary analysis reported here we have sought to identify and quantify recurring themes and terms that appear in responses. According to this analysis, hard work is the single most cited explanation provided to account for research success (26\%). This response often appears in combination with similar notions such as perseverance, tenacity, persistence, drive, and determination. Around $40 \%$ of respondents mentioned one or other of these terms as key to their success.

Having a mentor and/or mentoring from others is the next most often cited reason for success, at $19 \%$, and a similar proportion, at $17 \%$, cite support from either colleagues, family or peers as contributing to their success. A further $7 \%$ cite collaboration, either with colleagues or mentors, as contributing to their success. Overall, around 35\% of respondents attribute their success in part to enabling relationships with others, rather attributing their success entirely to their own efforts.

Another frequently mentioned factor in responses is 'passion', 'enjoyment' or 'love' of research. Taken together, these terms appear in $13 \%$ of responses. This confirms other 
studies that note the presence of passion and/or emotional investment in research amongst researchers (Akerlind, 2008; Bowden, Green, Barnacle, Cherry \& Usher, 2005) amongst doctoral candidates and early career researchers (Hakala, 2009; McAlpine, 2012; McAlpine \& Amundsen, 2009; Turner \& McAlpine, 2011) and in accounts of doctoral experience (Sinclair, 2009).

The importance of publications is mentioned by $12 \%$ of respondents and a similar percentage specifically mention the positive contribution of their $\mathrm{PhD}$ - either in terms of networks of relationships established, skills acquired or mentoring and supervision - to their mid-career success.

A potentially complicating factor is the relative frequency with which respondents attribute their success to 'luck', which is mentioned in $13 \%$ of responses. Attributing success in part to 'luck' may indicate some respondents are unable or unwilling 'rationally' to account for their own success; or that achieving 'success' is, at least in part, perceived explicit as due to factors beyond their control. Martin (2009) suggests, citing Wiseman that ostensibly 'lucky' people are actually attuned and responsive to opportunities (2009: 16-17). In other words, luck is created through personal attributes rather than random.

This analysis has identified key categories invoked by respondents in accounting for their success; however the richness of the data is contained in the varieties of combinations of the categories. For example:

Excellent mentoring; hard work; strong motivation.

Hard work, and some good luck! Also a well-timed publication in a high impact journal.

I would think it is attributed to my strong interest in research as well as the perseverance over the years. In addition, I would also attribute [it] to the support of fellow colleagues and students and the ability to work in a team.

Enjoy my research area, driven and motivated person.

The supports I received from my family, Faculty, University and ARC; my PhD training; my curiosity about the world and internal driver to excel.

Further analysis is required to understand more fully how successful researchers manage and meld the multiple demands and requirements of becoming a successful researcher and the disciplinary factors involved. The variety of combinations and factors 
suggest that becoming a successful researcher is as much an art as a science, in spite of efforts to specify ever more precisely the elements of a successful researcher. The Vitae Researcher Development Framework (2012), developed in the UK, for example, identifies four domains and 63 sub-domains of researcher development.

What is notable through this preliminary analysis, however, is an apparent emphasis in these accounts on what might be termed 'soft skills': of access to mentoring, support from various others, networking, personal motivations and inner drive, rather than an emphasis on instrumental expertise in the skills of research. The accounts also suggest a capacity to combine such soft skills in various ways, indicating a responsive, adaptive, or creative disposition. It may be that such a disposition contributes to becoming a successful researcher, and may even be essential given the largely tenuous and uncertain nature of research work. Examples of the dynamic combinations of these various skills and attributes are follows:

Tenacity, the ability to handle it when things go wrong, whether in research or with professional relationships. The ability to see things through, being well organised, able to adapt and try to make the most of opportunities. A positive outlook helps as well. Some personal drive. Real enjoyment of what I do.

Very hard work for many years. Luck; getting a couple of breaks that put me on a profitable trajectory. Courage in sticking my neck out and finding the right collaborators. Stubbornness (I only have a few ideas so I better make them work); knowing the rules of the game (to publish, get grants); grantsmanship; being able to have many balls in the air and only dropping a few; having a knack for seeing what fashion is coming next in fluctuating research fields; resilience/arrogance. I move on from hurtful journal rejections after about 10 minutes; being good at thinking up sexy titles for my papers.

These accounts suggest to us that successful researchers have what might be termed an 'entrepreneurial subjectivity', that is, a capacity to draw from a sophisticated and complex ensemble of soft skills, attributes and capacities and combine them as required in order to identify research opportunities and do research. In terming this capacity an 'entrepreneurial subjectivity' we are not referring to entrepreneurship in the sense of turning research to commercial advantage, rather we are suggesting that successful researchers adopt an enterprising attitude towards research and research work.

\section{Discussion}


The findings from this study confirm that further sustained work is warranted to better understand the connections and continuities between the doctoral experience and a productive research career. This preliminary analysis, however, identifies a number of key findings regarding the impact and influence of the doctorate on a later research career and to researcher formation.

Firstly, it appears that successful mid-career researchers often have positive doctoral experiences. While this does not necessarily mean that all candidates who have a positive doctoral experience will go on to become successful researchers, it does suggest that having a poor experience is unlikely to lead to later research success. The high level of enjoyment reported by our cohort with all dimensions of doctoral candidature suggests it is a key site in which to discover joy for research. Further, it seems the majority also learned how to research and what it is to be a researcher during doctoral candidature. This is evidenced by high responses to the question of how well the doctoral experience prepared them for a research career. It is interesting to speculate whether those in this cohort are the beneficiaries of supervisors who conceptualise their supervisory role in these terms. That is, not just in terms of guiding candidates to successful completion but also beyond to a successful research career. It would useful to pursue such issues further by investigating the supervisors of subsequently productive researchers.

Secondly, this sense of research efficacy evidenced by this cohort of Future Fellows may be tied in part to their publication productivity during candidature. This cohort appears to be particularly productive during doctoral candidature, confirming studies that suggest doctoral productivity is a predictor of future productivity (Williamson \& Cable, 2003); and that read productivity during candidacy as an indicator of high research performance (Gu et al., 2011). Again, the role of the supervisor appears to be influential in encouraging and establishing research efficacy in this area, particularly through the practice of co-publication during candidature, with potentially several benefits for candidates. If a candidate has successful experiences of co-authoring during candidature, arguably their formation as a researcher will be more advanced than a candidate who has not published nor even attempted to write for publication during candidature. The motivational benefits of the process of writing for publication and succeeding, thereby establishing a sense of research efficacy, may be just as or more important than the skill itself. 'Making progress' in work has been identified as the most effective way of boosting emotions, motivations and creativity (Amabile \& Kramer, 2011). Alternatively, the kind of supervision this cohort received may be more akin to a mentoring relationship, a relationship that has been positively associated with both research productivity and self-efficacy (Paglis, Green \& Bauer 2006). 
Thirdly, our findings point to an enduring sense of curiosity and engagement with the work of research as a prime motivation of productive researchers. The intensity of affect amongst the responses to the question regarding motivations for doing research is at times, frankly, quite moving. We have no option but to accept the sincerity of the sentiments expressed, despite a world-weary cynicism that sometimes circulates anecdotally about 'successful researchers' and 'the research game.' The picture here is not entirely rosy some have flourished despite less than optimal experiences, and some are rather more pragmatic in their approach. However, the prevalence of what appears to be a genuine enthusiasm for discovery and curiosity lead us to suggest that this cohort of successful researchers may understand their role more in terms of a 'calling'. Further work is required to establish how and when this sense of vocation develops, how it is sustained, and how it shapes motivations and productivity. Understanding a job as a 'calling' however has been linked to higher productivity (Achor, 2011: 78).

Paglis, Green and Bauer note the popularity of the notion of a successful senior role model influencing a protégé to follow a similar path. Findings here may suggest this narrative is at work in forming productive researchers. However, contra this view, Paglis, Green and Bauer's research on the effect of advisors' (or supervisors') mentoring found that mentoring in doctoral candidature has no measurable impact on research career commitment (2006: 47). They suggest, rather, that protégés have pre-existing high levels of commitment to a research career. Similar results have been found in studies of undergraduates offered research opportunities. That is, that such research experiences tend to confirm pre-existing levels of interest in research (Cuthbert et al. 2012; Joanna \& Creighton 2011). In view of this and our findings, the incoming level of commitment to a research career may also be considered crucial to a later research career.

Finally, and related to the former point, our findings concerning to what respondents attribute their success point to the importance of what may be termed 'soft skills' in becoming a successful researcher, such as hard work, curiosity, collaborations, networking, support from various others and so on. In citing these kinds of factors, our cohort also indicate a capacity to recognise the importance and contribution of such soft skills, over and above, for example, excellent research skills and a sense of research efficacy. Further research is required to establish how and where these soft skills, or capabilities, are developed. Moreover, the responses indicate the presence of a flexible, adaptable and responsive disposition in the ways various combinations of skills are put to use. We call this art of managing the self and one's circumstances in enterprising ways an 'entrepreneurial subjectivity' and contend that this particular subjectivity may be crucial to what is required to 
become a researcher and, in particular, to becoming a successful researcher. While we have found that what is learned during the doctoral experience and the kind of doctoral experiences had by successful researchers appear positively to influence researcher formation, our findings also suggest this additional ingredient - an 'entrepreneurial subjectivity' - also plays a part in research success.

The entrepreneurial nature of a researcher is not widely acknowledged. Although some programs advocate framing career possibilities for doctoral graduates in terms of 'intellectual entrepreneurship' (Cherwitz \& Sullivan, 2002) what we are suggesting is that a successful research career may entail a particular subjectivity or disposition on the part of the researcher, without which individuals may be less likely to succeed.

This analysis of our findings can be interpreted negatively or positively. On the one hand, the 'entrepreneurial subjectivity' of a successful researcher suggested by our research can be understood as another example of the kind of subjectivity produced by broader contemporary conditions and regimes. Employment is often temporary, short-term, unstable and subject to increasing measures of performance, such that what we are terming an 'entrepreneurial subjectivity' is demanded of all workers, including younger researchers (Archer, 2008). Correspondingly, it can be argued an 'entrepreneurial subjectivity' or an 'enterprising self' (Adams, 2007: 89 - 92) is produced and demanded by a globally competitive research economy and by 'the enterprise university' (Marginson \& Considine, 2000). On the other hand, it may be that successful researchers adopt and develop an 'entrepreneurial subjectivity' as the means to be able to get to do and continue to do the research work they want to do for curiosity or other reasons, in the face of challenging and competitive conditions. These questions require further investigation through additional research.

\section{Conclusion}

In summary, the findings reported here point to a positive doctoral experience and early establishment of research efficacy as important to researcher formation. In addition, the findings point to successful researchers having a repertoire of 'soft skills' and a flexible, responsive and adaptive disposition. In this paper we have argued that this flexible, responsive and adaptive disposition - what we are terming 'an entrepreneurial subjectivity' is an important and under examined characteristic of successful researchers. 
The value of the research project reported here and our analysis thus far is that it begins the work of examining more closely the contribution of the doctoral experience to researcher formation and a successful research career. There are some limitations of this work, however, that need to be noted. Firstly, the cohort is dominated by the science disciplines, reflecting the character of the Future Fellowship cohort overall. Secondly, our work here does not address the politics of research within departments and institutions, including gender politics, although we acknowledge these may be important factors in research career success. We also acknowledge we have taken a particularised, largely individualised approach to the question of doctoral experiences and a later research career and that departmental, disciplinary and institutional cultures are also influential to research careers. Future work on these issues will add to the work begun here of conceptualising doctoral experience and research productivity as inter-connected, rather than separate concerns.

\section{References}

Adams, M. (2007). Self and social change. London: Sage.

Achor, S. (2011). The happiness advantage: The seven principles that fuel success and performance at work. New York: Crown Business.

Archer, L. (2008). Younger academics' constructions of 'authenticity', 'success' and professional identity. Studies in Higher Education, 33(4), 385-403.

Australian Research Council. Future Fellowships. Retrieved July 30, 2012, from http://www.arc.gov.au/ncgp/futurefel/future_default.htm

Aitchison, C., Kamler, B., \& Lee, A. (2010). Publishing pedagogies for the doctorate and beyond. Oxford: Routledge.

Amabile, T., \& Kramer, S. (2011). The progress principle: using small wins to ignite joy, engagement, and creativity at work. Cambridge: Harvard University Press.

Akerlind, G. (2008). An academic perspective on research and being a researcher: an integration of the literature. Studies in Higher Education, 33(1), 17-31.

Bazeley, P. (2010). Conceptualising research performance. Studies in Higher Education, 35(8), 889-903.

Bentley, P. (2012). Gender Differences and factors affecting publication productivity among Australian university academics. Journal of Sociology, 48, 85-103. 
Bowden, J., Green, P., Barnacle, R., Cherry, N., \& Usher, R. (2005). Academics' ways of understanding success in research activities. In J. Bowden \& P. Green (Eds.), Doing Developmental Phenomenography (28-44). Melbourne: RMIT Press.

Brew, A., Boud, D., \& Namgung, S. (2011). Influences on the formation of academics: the role of the doctorate and structured development opportunities. Studies in Continuing Education, 33(1), 51-66.

Cherwitz, R.A., \& Sullivan, C. A. (2002, November-December). Intellectual entrepreneurship: a vision for graduate education. Change, 23-7.

Chung, J. Y., \& Petrick, J. (2011). Doctoral students' research productivity: An analysis of publications in tourism and hospitality journals. Journal of Hospitality, Leisure, Sport \& Tourism Education, 10(1), 63-71.

Cuthbert, D., Arunachalam, D., \& Licina, D. (2012). 'It feels more important than other classes I have done': an 'authentic' undergraduate research experience in sociology. Studies in Higher Education, 37(2), 129-42.

Cuthbert, D., \& Spark, C. (2008). Getting a GRiP: Examining the outcomes of a pilot program to support graduate research students in writing for publication. Studies in Higher Education, 33(1), 77-88.

Delamont, S., Atkinson, P., \& Parry, O. (2007). Supervising the doctorate: a guide to success. Maidenhead: Open University Press.

Gu, J., Lin, Y., Vogel, D., \& Tian, W. (2011). What are the major impact factors on research performance of young doctorate holders in science in China: a USTC survey. Higher Education, 62, 483-502.

Green, B. (2005). Unfinished business: subjectivity and supervision. Higher Education Research and Development, 24(2), 151-163.

Hesli, V., \& Mook Lee, J. (2011). Faculty research productivity: Why do some of our colleagues publish more than others? PS: Political Science and Politics, 44, 393-408.

Hakala, J. (2009). The future of the academic calling? Junior researchers in the entrepreneurial university. Higher Education, 57(2), 173-90.

Joanna, J., \& Creighton, J. (2011). Researcher development: The impact of undergraduate research opportunity programmes on students in the UK. Studies in Higher Education, 36(7), 781-97.

Lee, A., \& Boud, D. (2009). Producing researchers: the changing role of the doctorate. In A. Brew \& L. Lucas (Eds.), Academic research and researchers (96107). Maidenhead: Society for Research into Higher Education and Open University Press.

McAlpine, L. (2012). Identity-trajectories: Doctoral journeys from past to present to 
future. Australian Universities Review, 54(1), 38-47.

McAlpine, L., \& Amundsen, C. (2009). Identity and agency: Pleasures and collegiality among the challenges of the doctoral journey. Studies in Continuing Education, 31(2), 109-25.

Marginson, S., \& Considine, M. (2000). The enterprise university: Power, governance and reinvention in Australia. Cambridge: Cambridge University Press.

Martin, B. (2009). Research productivity: Some paths less travelled. Australian Universities Review, 51(1), 15-20.

Paglis, L., Green, S., \& Bauer, T. (2006). Does adviser mentoring add value? A longitudinal study of mentoring and doctoral student outcome. Research in Higher Education, 47(4), 451-76.

Raddon, A. E. (2011). A changing environment: Narratives of learning about research. International Journal for Researcher Development, 2(1), 26-45.

Russo, G. (2011, July). Postgraduate students: Aspirations and anxieties. Nature, 475, 5335 .

Roy, K., Roberts, M. C., \& Stewart, P. K. (2006). Research productivity and academic lineage in Clinical Psychology: Who is training the faculty to do research? Journal of Clinical Psychology, 62(7), 893-905.

Sinclair, J. (2009). Discipline and pleasure: unlikely lessons learned from doctoral candidacy (106-112). In C. Denholm and T. Evans (Eds.), Beyond Doctorates Downunder: maximizing the impact of your doctorate from Australia and New Zealand, Camberwell: ACER Press.

Turner, G., \& McAlpine, L. (2011). Doctoral experience as researcher preparation: Activities, passion, status. International Journal for Researcher Development, 2(1), 46-60.

Vitae. (2012a). What do researchers want to do? The career intentions of doctoral researchers. Cambridge: Career Research \& Advisory Centre (CRAC) Ltd.

Vitae. (2012). Researcher Development Framework. Retrieved September 12, 2012 from http://www.vitae.ac.uk/researchers/428241/Researcher-Development-Framework.html

Walker, G. E., Golde, C. M., Jones, L., Conklin Bueschel, A., \& Hutchings, P. (2008).

The formation of scholars: Re-thinking doctoral education for the twenty-first century. Stanford: The Carnegie Foundation for the Advancement of Teaching.

Williamson, I., \& Cable, D. (2003). Predicting early career research productivity: the case of management faculty. Journal of Organizational Behaviour, 24(1), 25-44. 
